\title{
Impedance technology for the management of esophageal disorders
}

\author{
Tutuian, R
}

\begin{abstract}
BACKGROUND: Esophageal impedance measurements are increasingly used to identify and quantify the presence of fluids in the esophagus. METHOD: A review of the available literature on clinical applications of impedance including combined impedance-manometry testing and combined impedancepH monitoring is done. RESULTS: Combined impedance-manometry testing offers the opportunity to quantify esophageal bolus transit and clarifies the implications of esophageal motility abnormalities on esophageal function. This is of particular interest in patients with non-obstructive dysphagia and in patients with post-fundoplication dysphagia. Combined impedance-pH monitoring allows the detection of gastroesophageal reflux episodes independent of $\mathrm{pH}$. This is of particular importance when evaluating patients with persistent symptoms on acid suppressive therapy. The ability to detect gastroesophageal reflux episodes with $\mathrm{pH}>4$ unfolds new questions on the optimal approach to patients with symptomatic non-acid reflux. CONCLUSIONS: Impedance technology allows the detection of fluid movements in the esophagus; further studies will determine the clinical utility of this new information.
\end{abstract}

DOI: https://doi.org/10.1007/s10353-008-0393-1

Posted at the Zurich Open Repository and Archive, University of Zurich ZORA URL: https://doi.org/10.5167/uzh-156477

Journal Article

Published Version

Originally published at:

Tutuian, R (2008). Impedance technology for the management of esophageal disorders. European Surgery, 40(2):50-57.

DOI: https://doi.org/10.1007/s10353-008-0393-1 


\title{
Impedance technology for the management of esophageal disorders
}

\author{
R. Tutuian \\ Division of Gastroenterology and Hepatology, Department of Internal Medicine, University Hospital Zurich, Zurich, Switzerland
}

Received February 8, 2008; accepted February 12, 2008

\section{Imedanzmessungen im Ösophagus - Klinische Anwendungen}

Zusammenfassung. Grundlagen: Impedanzmessungen im Ösophagus werden zunehmend häufiger zur Erkennung und Quantifizierung der Präsenz von Flüssigkeiten in der Speiseröhren eingesetzt.

Methodik: Übersicht der klinischen Anwendungen von Impedanzmessungen, insbesondere kombinierte Impedanz-Manometrie und Impedanz-pH-Metrie.

Ergebnisse: Kombinierte Impedanz-Manometrie ermöglicht die Quantifizierung des Bolustransites und klärt, inwiefern ösophageale Motilitätsabnormalitäten von einer Bolustransitstörung begleitet sind. Dies ist von besonderem Interesse für Patienten mit nicht-obstruktiver (i.e. funktioneller) Dysphagie und Patienten mit post-operativer Dysphagie.

Kombinierte Impedanz-pH-Metrie identifiziert Refluxepisoden unabhängig vom Säuregehalt (i.e. pH). Dieses ist wichtig für Patienten mit persistierenden Beschwerden trotz säurehemmender Therapie. Die Möglichkeit Refluxepisoden mit $\mathrm{pH}>4 \mathrm{zu}$ identifizieren, bringt neue Fragen betreffend der optimalen Therapie für Patienten mit symptomatischem nicht-saurem Reflux.

Schlussfolgerungen: Impedanzmessungen ermöglichen uns Flüssigkeitsbewegungen in der Speiseröhre zu identifizieren. Die klinische Wertigkeit dieser zusätzlichen Information dürfte durch zukünftige Studien geklärt werden.

Schlüsselwörter: Ösophagusmanometrie, ösophageale $\mathrm{pH}$-Metrie, Impedanzmessungen, kombinierte Impedanz-Manometrie, kombinierte Impedanz-pH-Metrie.

Correspondence: Radu Tutuian, Division of Gastroenterology and Hepatology, Department of Internal Medicine, University Hospital Zurich, Raemistrasse 100, 8091 Zurich, Switzerland.

Fax: ++41-44-255 4503

E-mail: radu.tutuian@access.uzh.ch
Summary. Background: Esophageal impedance measurements are increasingly used to identify and quantify the presence of fluids in the esophagus.

Method: A review of the available literature on clinical applications of impedance including combined impedance-manometry testing and combined impedance-pH monitoring is done.

Results: Combined impedance-manometry testing offers the opportunity to quantify esophageal bolus transit and clarifies the implications of esophageal motility abnormalities on esophageal function. This is of particular interest in patients with non-obstructive dysphagia and in patients with post-fundoplication dysphagia.

Combined impedance-pH monitoring allows the detection of gastroesophageal reflux episodes independent of $\mathrm{pH}$. This is of particular importance when evaluating patients with persistent symptoms on acid suppressive therapy. The ability to detect gastroesophageal reflux episodes with $\mathrm{pH}>4$ unfolds new questions on the optimal approach to patients with symptomatic nonacid reflux.

Conclusions: Impedance technology allows the detection of fluid movements in the esophagus; further studies will determine the clinical utility of this new information.

Keywords: Esophageal manometry, esophageal pH monitoring, multichannel intraluminal impedance (MII), combined impedance manometry, combined impedance-pH monitoring.

\section{Introduction}

In 1991, Silny described a novel modality for evaluating bolus movement in hollow gastrointestinal viscera by means of electrical impedance measurements [1]. In the years that followed, multichannel intraluminal impedance (MII) has been developed from a research to a clinical tool. Currently, it is used to clarify esophageal bolus transit in various esophageal motility abnormalities and thus it changed the paradigm of gastroesophageal reflux 
testing. The addition of impedance to conventional esophageal manometry (combined impedance-manometry testing) allows assessing bolus presence and transit without the use of radiating energy. The addition of impedance to $\mathrm{pH}$ monitoring (combined impedance-pH monitoring) allows detecting gastroesophageal reflux episodes independent of their acid content and allows distinguishing between liquid, gas and mixed reflux episodes.

\section{Methods}

This contribution highlights basic concepts of impedance testing and clinical applications of combined impedancemanometry testing and impedance- $\mathrm{pH}$ monitoring. Statistics were not applied.

\section{Results}

\section{Basic concepts and validation of bolus transit measurements assessed by multichannel impedance}

The basic component of MII testing is the impedance circuit. Alternating current is applied to two steel rings mounted on a catheter creating an impedance-measuring segment. Because the catheter is not conducting electrical current, the presence of electrical charges around the catheter is required to close the electrical circuit. When placed inside the esophagus, ions in the esophageal mucosa will close the electrical circuit and the system will measure a relative stable impedance baseline of 1500$3000 \mathrm{Ohm}$. The presence of liquids within the impedancemeasuring segment (i.e. between the two steel rings) improves electrical conductivity and the system will mea- sure low impedance values. The appearance of a liquid bolus in the impedance-measuring segment induces a rapid decline in impedance, which will remain low as long as the bolus bridges both rings. Once the esophageal peristalsis clears the bolus out of the impedance-measuring segment, impedance values raise and return to baseline. Conversely, the presence of air in the impedance- measuring segment decreases electrical conductivity and the system will measure high impedance values. The appearance of gas in the impedance-measuring segment will produce a rapid rise in intraluminal impedance, which will then return to baseline once the air bolus passes out of the impedance-measuring segment. These declines and raises in intraluminal impedance are used to determine the presence of liquid, gas and mixtures of liquids and gas within the esophagus. By convention liquid bolus entry point is declared when impedance decreases by $50 \%$ from baseline to nadir and bolus exit when impedance rises back to this $50 \%$ value. The entry point of gas is declared when there is a sudden rise in impedance of more than 3000 Ohms above baseline. In the case of mixed (i.e. liquid-gas or gas-liquid) boli, bolus entry and exit points are declared when impedance drops recovers to the $50 \%$ value between baseline and nadir.

Mounting multiple impedance-measuring segments on the same catheter allows not only detecting bolus presence at various levels inside the esophagus but also determining the direction of bolus movement within the esophagus. Changes in impedance occurring in time from proximal to distal indicate an antegrade bolus movement as seen during swallowing while impedance changes occurring in time from distal to proximal indicate a retrograde bolus movement as seen during reflux (Fig. 1). The ability to distinguish between liquid and gas allows mul-

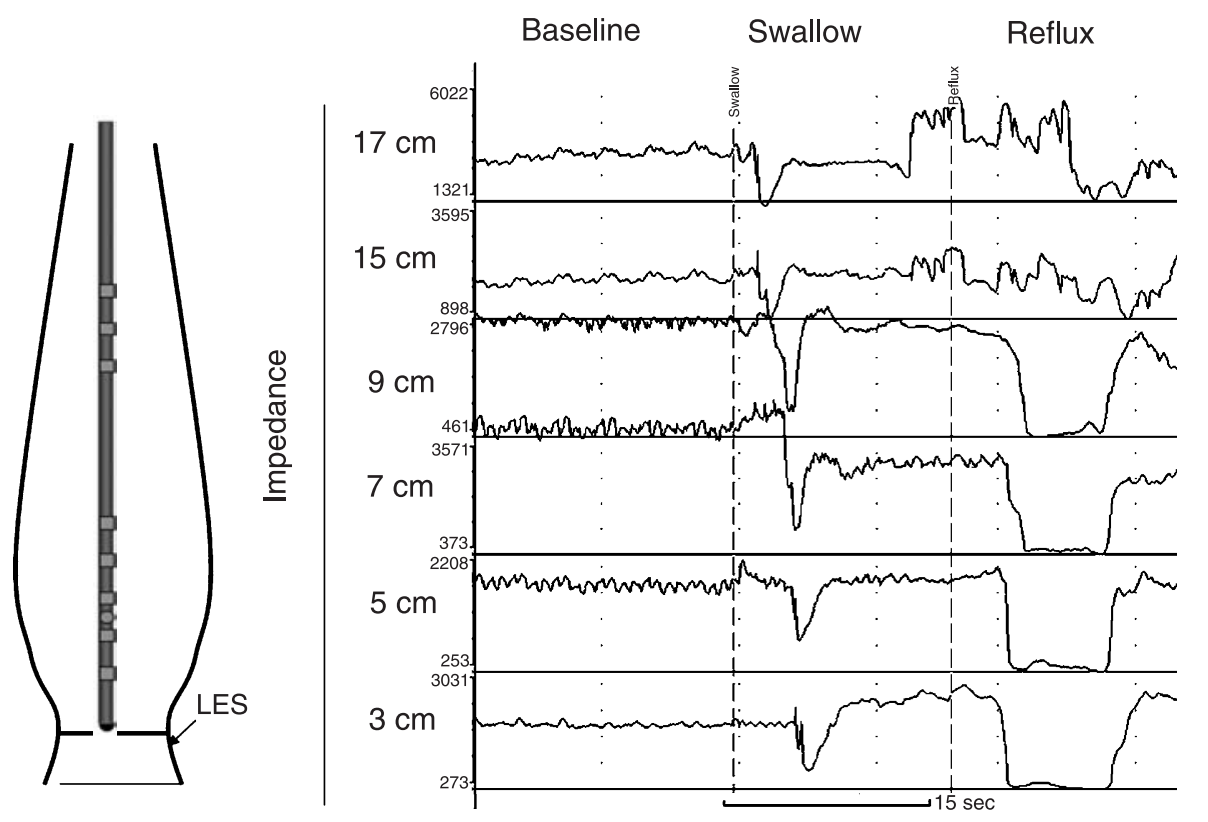

Fig. 1: Swallow and reflux episode identified by multichannel intraluminal impedance. Multiple impedance segments mounted on the same catheter (left) identify antegrade bolus movements (i.e. swallows) as changes in intraluminal impedance baseline advancing over time from the proximal to distal channel and retrograde bolus movements (i.e. reflux episodes) as changes in intraluminal impedance advancing over time from distal to proximal. In this example, the reflux episode reaches a height of $9 \mathrm{~cm}$ above the LES 


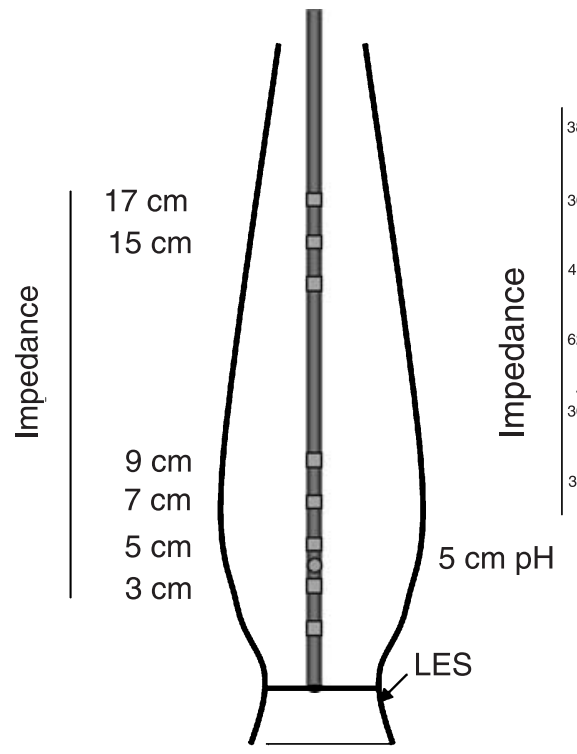

Liquid

Mixed

Gas

Fig. 2: Examples of liquid, mixed and gas reflux episodes identified during combined impedance pH monitoring. Liquid-only reflux episodes are identified as rapid decline in impedance advancing from distal to proximal. Gas-only reflux episodes are identified as rapid increases in impedance advancing from distal to proximal channel. Mixed (gas-liquid) reflux episodes include features of both gas (rise in impedance) and liquid (decline in impedance) changes in impedance

tichannel intraluminal impedance to characterize the physical properties of the refluxate and classify reflux episodes as liquid, gas or mixed (Fig. 2).

The ability of multichannel intraluminal impedance to detect bolus movement has been validated by Silny et al. [2] and Simren et al. [3] based on synchronized videofluoroscopy and impedance recordings. Considering bolus entry at a $50 \%$ drop in impedance from baseline to nadir and bolus exit at the recovery of impedance to the $50 \%$ value, Simren et al. [3] found a strong correlation between both methods for the measurement of the time to esophageal filling $(r=0.94 ; p<0.0001)$ and time to esophageal emptying $(r=0.89 ; p<0.0001)$. Evaluating the correlation between impedance and barium swallows in 13 healthy volunteers, Iman et al. found an agreement between barium and impedance bolus transit or stasis in 97\% (72/74) of swallows [4].

In summary, impedance measurements can detect liquid, gas and mixed bolus presence in the esophagus and quantify liquid bolus presence as the time elapsed between the $50 \%$ drop in impedance from baseline to nadir to the recovery of impedance to the $50 \%$ value. Using multiple impedance measuring segments (MII), one can determine bolus presence at multiple levels in the esophagus and distinguish swallowing from reflux episodes.

\section{Esophageal function testing using combined impedance-manometry}

Esophageal manometry is the gold standard in evaluating esophageal dysmotilities. In the past years, increasing computing power and miniature sensors allowed the development of high-resolution manometry and topographic plotting of the signal [5]. While providing information on amplitude, duration and peristaltic sequence of esophageal contraction, manometry provides only indirect information on esophageal bolus transit, the actual function of the esophagus. Until recently, esophageal function was determined mainly with barium videofluoroscopy. Combining manometry with videofluoroscopy improved our understanding of esophageal peristalsis but is not suitable for routine clinical use because of the use of radiation (limiting the number of swallows to be evaluated) and the need to coordinate and schedule both procedures (manometry and barium videofluoroscopy) in the same time-slot.

The addition of impedance channels to a manometry channel does not change the external dimension of the catheter and, from a patient's perspective combined impedance manometry is no different than conventional manometry. Indications for combined impedance-manometry are the same for conventional manometry [6]. Owing to the good correlation and agreement of impedance and fluoroscopy (see above) combined impedance manometry offers the opportunity to evaluate both pressure changes and bolus transit during the same swallows and, since there is no radiating energy allows investigating an unlimited number of swallows.

Studies in normal volunteers by Srinivasan et al. confirmed the ability of MII to characterize bolus transit through the esophagus of liquid, semisolids and solid boluses [7]. Noticing the same changes in intraluminal impedance during swallowing of liquid boluses from $1 \mathrm{cc}$ to $10 \mathrm{cc}$ confirmed the high degree of sensitivity in identifying bolus presence but limited ability of impedance to estimate volumes of intraesophageal boluses.

In an initial step of introducing impedance-manometry into clinical practice was establishing normal values. In a multicenter study, we established normal values for this technique based on data from 43 healthy US 

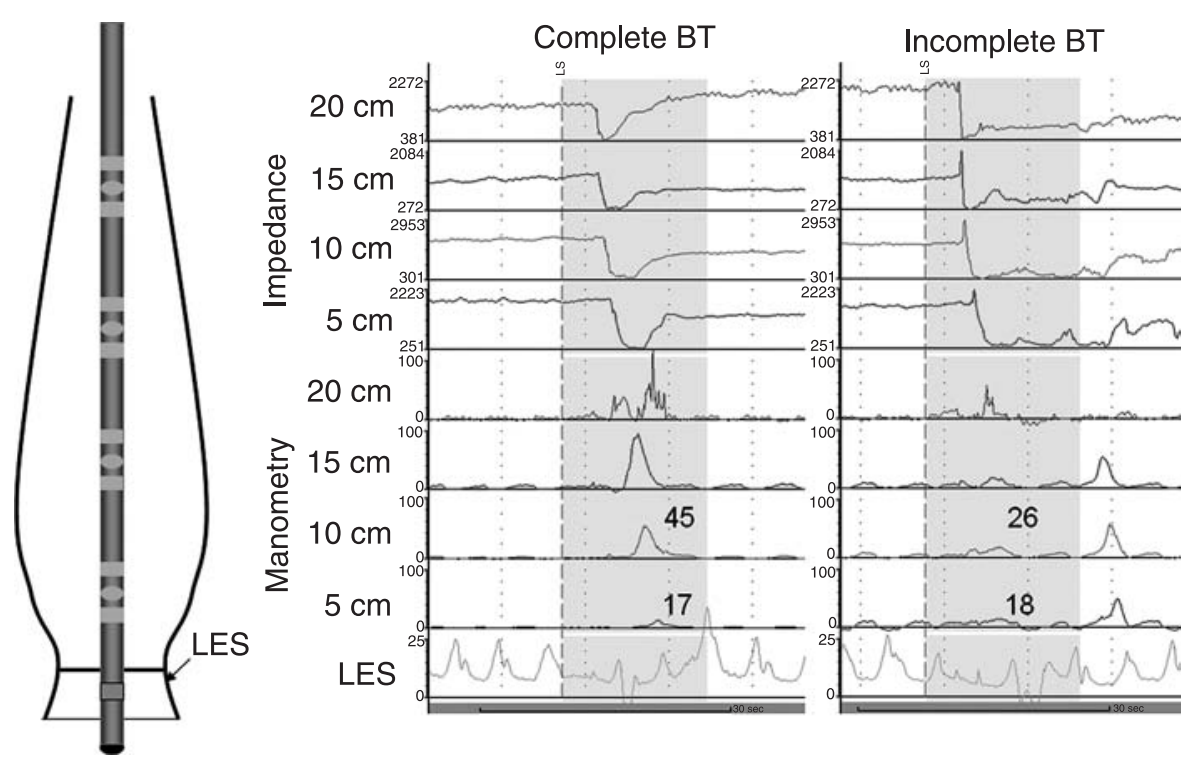

Fig. 3: Combined impedance-manometry tracings depict examples of manometric ineffective contractions with complete and incomplete bolus transit. Combined impedance-manometry catheter has circumferential pressure transducer in the LES, and matching impedance-manometry channels at $5,10,15$ and $20 \mathrm{~cm}$ above the LES. Both contractions are manometric ineffective as the pressure in at least one distal channel is below $30 \mathrm{mmHg}$. The first swallow has complete bolus transit defined as bolus entry in the proximal and bolus exit in all three distal channels. The second swallow has incomplete bolus transit defined as missing bolus exit in at least one distal channel

volunteers [8]. Analyzing esophageal bolus transit of 10 saline and 10 viscous swallows, we found that more than $90 \%$ of healthy volunteers cleared at least $80 \%$ of liquid swallows and at least $70 \%$ of viscous swallows. Examples of swallows with complete and incomplete bolus transit are shown in Fig. 3. These values were later confirmed by a Dutch-Australian multicenter study in 42 healthy volunteers using combined water-perfused manometry-impedance systems [9]. A third set of normal data for combined impedance-manometry testing was reported by Nguyen et al. in a group of 25 healthy subjects [10]. Bolus transit parameters were similar to prior studies albeit using yoghurt as semisolid test substance. Of particular interest in Nguyen's study are normal values of the esophageal impedance baseline and deglutitive impedance gradient during saline and yoghurt swallows.

The next step in evaluating the use of combined impedance-manometry in clinical practice was evaluating if evaluating bolus transit translates in additional information compared to conventional manometry. Using combined impedance-manometry in 350 consecutive patients with various manometric abnormalities, we characterized bolus transit abnormalities in these groups of patients [11]. We found abnormal bolus transit for liquid (i.e. incomplete bolus transit for at least $30 \%$ of liquid swallows) and viscous (i.e. incomplete bolus transit for at least $40 \%$ of liquid swallows) in all patients with achalasia and scleroderma proving the ability of impedance measurements to detect predictable severe transit abnormalities. Conversely, normal bolus transit for liquid was identified in at least $95 \%$ of patients with normal manometry, nutcraker esophagus and isolated LES abnormalities (i.e. poorly relaxing LES, hypertensive and hypotensive LES). Approximately half of patients with ineffective esophageal motility (IEM) and distal esophageal spasm (DES) had normal bolus transit for liquid.

Following up on the bolus transit abnormalities identified in patients with IEM, we evaluated manometric predictors for normal bolus transit in these patients [12]. Data from 70 IEM patients indicated that there is no perfect (i.e. highly sensitive and highly specific) manometric cutoff to predict complete bolus transit and that the current manometric criteria for diagnosing IEM (i.e. $30 \%$ or more manometric ineffective swallows) is so sensitive and lacks the specificity for identifying contractions accompanied by abnormal bolus transit. In addition, when analyzing bolus transit for liquid and viscous swallows, we found that approximately one third of patients with IEM had normal bolus transit for liquid and viscous (i.e. mild functional defect), approximately one third had abnormal bolus transit for either liquid or viscous (i.e. moderate functional defect) and another third abnormal bolus transit for both liquid and viscous (i.e. severe functional defect). The clinical utility of stratifying IEM in groups of patients mild, moderate and severe function abnormalities depends on the outcome of studies evaluating the potential this grading scheme to identify patients at risk for developing post-operative dysphagia.

Conchillo et al. reported on the role of combined impedance-manometry in patients with non-obstructive dysphagia [13]. Evaluating 40 patients with dysphagia in the absence of structural lesions (20 patients with normal motility, 13 IEM, 4 DES and 3 achalasia), the authors found abnormal transit for liquid and/or viscous boluses in $35.3 \%$ of patients with normal motility, $66.7 \%$ of DES patients and in $100 \%$ of patients with achalasia. These findings indicate that the addition of impedance to ma- 
nometry identifies esophageal function abnormalities in patients with non-obstructive dysphagia in which manometry would have been normal or unspecific.

Combined impedance-manometry has been recently employed to evaluate changes in esophageal function in untreated (38) and treated patients with achalasia (10 Botox or pneumatic dilatation and 16 Heller myotomy) [14]. Although esophageal function was not normalized by currently used criteria (i.e. $\geq 80 \%$ liquid swallows with complete bolus transit and $\geq 70 \%$ viscous swallows with complete bolus transit), Tatum et al. found a statistical significant $(p<0.05)$ difference in percentage of swallows with complete bolus transit between untreated patients (liquid $5 \%$, viscous $2 \%$ swallows with complete bolus transit) and patients after Heller myotomy (liquid 28\%, viscous $19 \%$ swallows with complete bolus transit).

Yigit et al. evaluated the role of impedance-manometry in evaluating patients with post-fundoplication dysphagia [15]. The analysis of impedance-manometry tracings in 80 patients undergoing Nissen fundoplication (52 with and 28 without dysphagia) revealed similar ( $p=$ ns) proportions of patients with abnormal esophageal peristalsis in the group complaining of dysphagia (17\%) and those without dysphagia (14\%) but an increased $(p<0.01)$ proportion of patients with abnormal bolus transit in the dysphagia (61\%) vs. the non-dysphagia (32\%) group. These findings suggest that evaluating esophageal bolus transit may be more important than esophageal peristalsis in post-fundoplication dysphagia.

In summary, present data indicate that combined impedance-manometry provides more information compared to conventional manometry. Information on bolus transit is important in explaining dysphagia in patients in whom conventional manometry would have indicated normal or minor abnormalities and in patients with post-fundoplication dysphagia. Further outcome studies are warranted to explore the ability of impedance-manometry to predict the development of post-fundoplication dysphagia.

\section{Reflux monitoring using combined impedance-pH monitoring}

Combined impedance-pH monitoring represents an important shift in the paradigm of reflux testing. Until recently, gastroesophageal reflux monitoring was similar to esophageal $\mathrm{pH}$ monitoring. Esophageal $\mathrm{pH}$ monitoring exploited the fact that gastric secretions have a high acid concentration (i.e. low $\mathrm{pH}$ values) and gastroesophageal content refluxing into the esophagus produces rapid declines in esophageal $\mathrm{pH}$. The ability of impedance measurement to detect bolus presence in the esophagus as changes in electrical conductivity within the esophagus allows monitoring gastroesophageal reflux episodes independent of their acid content. This is of particular importance given the use of proton pump inhibitors (PPI) in patients with or suspected to have gastroesophageal reflux. Because PPI trials are recommended as diagnostic tests for GERD in patients with symptoms suspected to be caused by reflux disease and the very convenient effect/side-effect profile of PPIs, many patients referred to gastrointestinal specialists with reflux symptoms are on or already tried PPI therapies. Consequently, there has been a shift in patients referred for testing from patients referred to diagnose GERD to patients with persistent symptom on acid suppressive therapy. In this situation, the ability to monitor gastroesophageal reflux episodes in patients on acid suppressive therapy is of pivotal importance.

Combined impedance-pH monitoring identifies gastroesophageal reflux episodes by changes in intraluminal resistance to alternating current (i.e. impedance) and data from the $\mathrm{pH}$ sensor are used to characterize the acid content of reflux episodes. Given previous experiences with $\mathrm{pH}$ monitoring gastroesophageal reflux episodes accompanied by a decline in reflux below $\mathrm{pH} 4$ are considered acid whereas reflux episodes with a pH above 4 are considered non-acid. In a recent consensus conference, 11 esophageal experts proposed a new set of definitions for reflux episodes identified by combined impedance-pH monitoring [16]. The revised classification maintains the same criteria for acid reflux (drop in $\mathrm{pH}$ from above to below 4) and coins reflux episodes occurring while esophagel $\mathrm{pH}$ is below 4 as "superimposed reflux". Acknowledging that solutions with a pH between 4 and 7 are acidic by chemical criteria the group proposed the term "weakly acidic" to MII-detected reflux episodes during which the pH is between 4 and 7 and the term "weakly alkaline" reflux to episodes during which the $\mathrm{pH}$ does not drop below 7 (Table 1).

The importance of combined impedance-pH monitoring has been highlighted by studies comparing gastroesophageal reflux off and on acid suppressive therapy.

Tab. 1: Traditional and revised classification of gastroesophageal reflux episodes

\begin{tabular}{llll}
\hline $\mathrm{pH}$ & $\mathrm{pH}$ monitoring & Impedance-pH monitoring & \\
\cline { 3 - 4 } & & Traditional classification & Revised classification (Oporto Group 2002 [14]) \\
\hline Less than 4 & Acid reflux & $\begin{array}{l}\text { Acid reflux (MII detected } \\
\text { reflux with } \mathrm{pH} \leq 4)\end{array}$ & $\begin{array}{l}\text { Acid reflux (MII detected reflux with drop in pH from } \\
\text { above to below 4) Superimposed reflux (MII detected } \\
\text { reflux starting while pH less than 4) }\end{array}$ \\
\hline Between 4 and 7 & No reflux & $\begin{array}{l}\text { Non-acid (MII detected } \\
\text { reflux with } \mathrm{pH}>4)\end{array}$ & Weakly acidic reflux \\
Greater than 7 & & Weakly alkaline reflux \\
\hline
\end{tabular}


Evaluating 12 patients with heartburn off medication and then after 7 days of omeprazole $20 \mathrm{mg}$ twice daily, Vela et al. found that in the post-prandial period acid suppressive therapy reduced the number of gastroesophageal reflux episodes with $\mathrm{pH}<4$ (i.e. acid reflux episodes) and led to an apparently paradoxical increase in gastroesophageal reflux episodes with $\mathrm{pH}>4$ (i.e. non-acid reflux episodes) the overall number of all reflux episodes (i.e. acid and non-acid reflux episodes) remained the same. These data underscored the concept that PPIs change only the acid content composition of gastroesophageal reflux in the post-prandial period.

Normal values for combined impedance-pH monitoring have been established in a multicenter study in 60 healthy volunteers [17]. Data in normal volunteers advocate that in the absence of acid suppressive therapy the vast majority of GER episodes are acidic, with non-acid GER episodes limited primarily to post-prandial periods. The chief interest in this study is the observation that the time intraesophageal $\mathrm{pH}$ is below 4 (detected by $\mathrm{pH}$ ) is much longer compared to the actual acid bolus presence time (detected by impedance) underscoring the observation that acid clearance requires not only the removal of the bolus but also the neutralization of the mucosal acid. These data confirm prior scintigraphic-pH data by Helm et al. that demonstrated that esophageal acid clearance time (assessed by $\mathrm{pH}$ ) was much longer compared to the time the radiolabeled $\mathrm{HCl}$ bolus was present in the esophagus [18]. In addition to the US-Belgian normal values, currently two more sets of normal values from FrenchBelgian [19] and Italian [20] cohorts of healthy volunteers not taking any acid suppressive therapy are available. While normal values proposed by the US-Belgian and French-Belgian cohort are similar, Italian normal values are somewhat lower (Table 2). This is most probably explained by Zentilin et al. who conducted the diet study; controlled food intake (Mediterranean diet)that produced less reflux episodes was compared to "ad libitum" diets used in the other studies.

Tab. 2: These are the normal values for combined impedance-pH monitoring based on $95^{\text {th }}$ percentile data in healthy volunteers not taking acid suppressive therapy

$\begin{array}{lll}\text { US-Belgian } & \text { French- } & \text { Italian } \\ {[17]} & \text { Belgian [18] } & {[20]} \\ (N=60) & (N=72) & (N=25)\end{array}$

\begin{tabular}{lllll}
\hline \multicolumn{4}{c}{ Esophageal pH data } \\
\hline \%time $\mathrm{pH}<4$ & total & $6.7 \%$ & $5.0 \%$ & $4.0 \%$ \\
& upright & $9.7 \%$ & $6.2 \%$ & $5.0 \%$ \\
& recumbent & $2.1 \%$ & $5.3 \%$ & $3.0 \%$ \\
\hline
\end{tabular}

Esophageal MII data

\begin{tabular}{lllll}
\hline \multirow{2}{*}{ Nr. reflux episodes } & total & 73 & 75 & 61 \\
& acid & 55 & 50 & 51 \\
& weakly acid & 26 & 33 & 38 \\
& weakly alkaline & 1 & 15 & 18 \\
\hline
\end{tabular}

Given the ability of combined impedance-pH monitoring to identify reflux episodes independent of $\mathrm{pH}$, this tool offers much scope to evaluate the relationship between persistent symptoms on acid suppressive therapy and reflux episodes. Studies evaluating the relationship between persistent symptoms on twice daily PPI therapy and reflux episodes by Mainie et al. [21] and Zerbib et al. [22] documented that in $40-50 \%$ of patients reporting esophageal symptoms during the monitoring had symptoms associated with gastroesophageal reflux. Because potent acid suppressive therapy (PPI bid) reduced gastric acid concentration, in most patients the association was positive for non-acid reflux. In a recent study, evaluating patients with persistent symptoms on PPI once daily, Becker et al. [23] reported abnormal impedance-pH findings (abnormal distal esophageal acid exposure or abnormal number of MII-detected reflux episodes) in 39\% of patients. Following up patients after escalated therapy for at least 3 months, the authors recorded a better $(p<0.01)$ symptomatic relief in patients with abnormal impedance$\mathrm{pH}$ results $(90 \%)$ compared to patients with normal impedance-pH findings (43\%). These findings promulgate that combined impedance-pH monitoring facilitates a more focused therapeutic approach to patients with PPIresistant GERD.

Another area of interest for combined impedance$\mathrm{pH}$ monitoring is patients with atypical GERD symptoms. Using combined impedance-pH monitoring Sifrim et al. evaluated 22 patients with persistent cough attributed to gastroesophageal reflux and spotted-10 patients (45\%) with a positive temporal association (i.e. positive symptom association probability; SAP) between cough and reflux [24]. These patients were investigated after abandoning acid suppressive therapy and half of them had a positive SAP for cough and acid reflux, $20 \%$ for cough and either acid reflux or weakly acidic reflux and $30 \%$ of patients for cough and weakly acidic reflux only.

Evaluating 50 patients with persistent cough on acid suppressive therapy, we found a positive symptom association between cough and non-acid reflux in 13 (26\%) patients on PPI bid \pm H2RA qhs [25]. Six patients with positive symptom index on impedance-pH monitoring underwent laparoscopic fundoplication and became asymptomatic off acid-suppressive therapy during followup evaluations (median time, 17 months; range, 12-27 months).

These studies imply that gastroesophageal reflux with a pH above 4 can play a vital role in the pathogenesis of chronic cough both in patients on or off acid suppressive therapy. These patients should be tested as finding a positive symptom association can have clinical implications.

The impact of impedance-pH monitoring on clinical management is currently scrutinized. Preliminary data suggest that patients with symptomatic non-acid reflux on acid suppressive therapy benefit from reflux-reducing interventions. In an observational study, Mainie et al. reported on the efficacy of laparoscopic fundoplication in patients with symptomatic reflux on PPI bid identified by impedance-pH monitoring [26]. Nineteen patients who underwent combined impedance-pH monitoring prior 
to laparoscopic fundoplication were followed up after a median 14 months (range 7-25) and asked if they still had symptoms or were taking PPIs. Out of the 18/19 patients with a positive symptom association during combined impedance-pH monitoring, 16/17 were asymptomatic or markedly improved (one patient was not followed up) and persistent symptoms occurred in one patient with negative symptom index on the pre-operative examination and another patient with positive symptom index for ENT symptoms and non-acid reflux. Albeit being an uncontrolled and not randomized study, this observation suggests that patients with documented positive symptom association with ongoing gastroesophageal reflux on acid suppressive therapy can be treated by laparoscopic fundoplication [27].

Rumination and aerophagia are two functional esophageal disorders in which impedance measurements can help establishing the correct diagnosis and direct management. According to the Rome II criteria, rumination is defined as a chronic or recurrent regurgitation of recently ingested food into the mouth with subsequent remastication and swallowing continue for at least 3 months in the absence of nausea and vomiting [28]. These patients are not aware of the involuntary increase in abdominal pressure leading to regurgitation of recently ingested food back into the esophagus and mouth. A hasty history may confound rumination with regurgitation attributed to GERD. Unlike GERD, rumination episodes are repeated many times during or immediately after a meal and stop once gastric content becomes acidic. Since most reflux episodes are non-acidic, attempts to identify rumination by conventional $\mathrm{pH}$ monitoring have been difficult. Combined impedance-manometry with pressure transducers placed into the stomach documented the sequence of rise in intraabdominal pressure successfully before each rumination episode and hereby objectively diagnose rumination [29].

Aerophagia is characterized by sucking air into the esophagus and belching it out before it reaches the stomach. Most patients complaining of belching are often evaluated for reflux disease or dyspepsia. Owing to the high sampling frequency $(50 \mathrm{~Hz})$, esophageal multichannel intraluminal impedance monitoring can identify the correct sequence of air being swallowed/sucked into the esophagus and then expelled rapidly (i.e. supragastric belching) [30]. Diagnosing these patients in a better fashion is important since patients with supragastric belching are likely to benefit from behavioral therapy and not from antireflux surgery.

In summary, combined impedance-pH monitoring identifies gastroesophageal reflux episodes independent of their acid concentration. This makes impedance$\mathrm{pH}$ monitoring the method of choice when evaluating patients with atypical reflux symptoms or patients with persistent symptoms on acid suppressive therapy. Preliminary data signal that patients with documented positive symptom association benefit from antireflux surgery. Impedance monitoring also offers the opportunity to identify and correctly diagnose functional esophageal disorders such as rumination and aerophagia.

\section{Conclusions}

Impedance technology offers clinicians and investigators to evaluate the movement of fluids (liquids and gas) in the esophagus. Combined with manometry, it helps to clarify the implications of abnormal peristalsis on esophageal bolus transit. Combined with $\mathrm{pH}$, it helps to clarify the mechanisms of persistent symptoms on acid suppressive therapy, identify the relationship between reflux and extraesophageal symptoms and offer the ability to document functional esophageal disorders objectively such as aerophagia and rumination. At the moment, outcome studies are warranted to enhance our understanding of the role of impedance testing in predicting the development of post-fundoplication dysphagia and in managing patients with symptomatic reflux on acid suppressive therapy.

\section{References}

[1] Silny J (1991) Intraluminal multiple electric impedance procedure for measurement of gastrointestinal motility. J Gastrointest Motil 3: 151-162

[2] Silny J, Knigge KP, Fass J, Rau G, Matern S, Schumpelick V (1993) Verification of the intraluminal multiple electrical impedance measurement for recording of gastrointestinal motiliy. J Gastrointest Motil 5: 107-122

[3] Simren M, Silny J, Holloway R, Tack J, Janssens J, Sifrim D (2003) Relevance of ineffective oesophageal motility during oesophageal acid clearance. Gut 52: 784-790

[4] Imam H, Shay S, Ali A, Baker M (2005) Bolus transit patterns in healthy subjects: a study using simultaneous impedance monitoring, videoesophagram, and esophageal manometry. Am J Physiol 288: G1000-G1006

[5] Bredenoord A (2007) High-resolution manometry - bliss upon bliss for esophagology? Eur Surg 39: 167-173

[6] Lenglinger J, Ringhofer C, Eisler M, Devyatko E, Cosentini E Wrba F, Zacherl J, Riegler M (2006) Diagnosis of Gastroesophageal Reflux Disease (GERD). Eur Surg 38: 227-243

[7] Srinivasan R, Vela MF, Katz PO, Tutuian R, Castell JA, Castell DO (2001) Esophageal function testing using multichannel intraluminal impedance. Am J Physiol 280: G457-G462

[8] Tutuian R, Vela MF, Balaji N, Wise JL, Murray JA, Peters JH, Shay SS, Castell DO (2003) Esophageal function testing using combined multichannel intraluminal impedance and manometry. Multicenter study of healthy volunteers. Clin Gastroenterol Hepatol 1: 174-182

[9] Nguyen NQ, Rigda R, Tippett $M$, Conchillo J, Smout AJ, Holloway RH (2005) Assessment of oesophageal motor function using combined perfusion manometry and multi-channel intraluminal impedance measurement in normal subjects. Neurogastroenterol Motil 17: 458-465

[10] Nguyen HN, Domingues GR, Winograd R, Koppitz P, Lammert F, Silny J, Matern S (2003) Impedance characteristics of normal oesophageal motor function. Eur J Gastroenterol Hepatol 15: 773-780

[11] Tutuian R, Castell DO (2004) Combined multichannel intraluminal impedance and manometry clarifies esophageal function abnormalities. Study in 350 patients. Am J Gastroenterol 99: 1011-1019

[12] Tutuian R, Castell DO (2004) Clarification of the esophageal function defect in patients with manometric ineffective esophageal motility: studies using combined impedance-manometry. Clin Gastroenterol Hepatol 2: 230-236

[13] Conchillo JM, Nguyen NQ, Samsom M, Holloway RH, Smout AJ (2005) Multichannel intraluminal impedance monitoring in the evaluation of patients with non-obstructive dysphagia. Am J Gastroenterol 100: 2624-2632

[14] Tatum RP, Wong JA, Figueredo EJ, Martin V, Oelschlager BK (2007) Return of esophageal function after treatment for achalasia as determined by impedance-manometry. J Gastrointest Surg 11: 1403-1409

[15] Yigit T, Quiroga E, Oelschlager B (2006) Multichannel intraluminal impedance for the assessment of post-fundoplication dysphagia. Dis Esophagus 19: 382-388 
[16] Sifrim D, Castell DO, Dent J, Kahrilas PJ (2004) Gastroesophageal reflux monitoring: review and consensus report on detection and definitions of acid, non-acid and gas reflux. Gut 53: 1024-1031

[17] Shay S, Tutuian R, Sifrim D, Vela M, Wise J, Balaji N, Zhang X, Adhami T, Murray J, Peters J, Castell D (2004) Twenty-four hour ambulatory simultaneous impedance and $\mathrm{pH}$ monitoring: a multicenter report of normal values from 60 healthy volunteers. Am J Gastroenterol 99: 1037-1043

[18] Helm JF, Dodds WJ, Pelc LR, Palmer DW, Hogan WJ, Teeter BC (1984) Effect of esophageal emptying and saliva on clearance of acid from the esophagus. N Engl J Med 310: 284-288

[19] Zerbib F, des Varannes SB, Roman S, Pouderoux P, Artigue F, Chaput U, Mion F, Caillol F, Verin E, Bommelaer G, Ducrotté P, Galmiche JP, Sifrim D (2005) Normal values and day-to-day variability of $24-\mathrm{h}$ ambulatory oesophageal impedance-pH monitoring in a Belgian-French cohort of healthy subjects. Aliment Pharmacol Ther 22: 1011-1021

[20] Zentilin P, Iiritano E, Dulbecco P, Bilardi C, Savarino E, De Conca S, Parodi A, Reglioni S, Vigneri S, Savarino V (2006) Normal values of 24 -h ambulatory intraluminal impedance combined with $\mathrm{pH}$-metry in subjects eating a Mediterranean diet. Dig Liver Dis 38: 226-232

[21] Mainie I, Tutuian R, Shay S, Vela M, Zhang X, Sifrim D, Castell DO (2006) Acid and non-acid reflux in patients with persistent symptoms despite acid suppressive therapy: a multicentre study using combined ambulatory impedance-pH monitoring. Gut 55: $1398-1402$

[22] Zerbib F, Roman S, Ropert A, des Varannes SB, Pouderoux P, Chaput U, Mion F, Vérin E, Galmiche JP, Sifrim D (2006) Esophageal $\mathrm{pH}$-impedance monitoring and symptom analysis in GERD: a study in patients off and on therapy. Am J Gastroenterol 101: 1956-1963

[23] Becker V, Bajbouj M, Waller K, Schmid RM, Meining A (2007) Clinical trial: persistent gastro-oesophageal reflux symptoms despite standard therapy with proton pump inhibitors - a follow-up study of intraluminal-impedance guided therapy. Aliment Pharmacol Ther 26: 1355-1360

[24] Sifrim D, Dupont L, Blondeau K, Zhang X, Tack J, Janssens J (2005) Weakly acidic reflux in patients with chronic unexplained cough during 24 hour pressure, $\mathrm{pH}$, and impedance monitoring. Gut 54: 449-454

[25] Tutuian R, Mainie I, Agrawal A, Adams D, Castell DO (2006) Nonacid reflux in patients with chronic cough on acid-suppressive therapy. Chest 130: 386-391

[26] Mainie I, Tutuian R, Agrawal A, Adams D, Castell DO (2006) Combined multichannel intraluminal impedance-pH monitoring to select patients with persistent gastro-oesophageal reflux for laparoscopic Nissen fundoplication. Br J Surg 93: 1483-1487

[27] Wykypiel H, Bonatti H, Hinder RA, Glaser K, Wetscher GJ (2006) The laparoscopic fundoplications: Nissen and partial posterior (Toupet) fundoplication. Eur Surg 38: 244-249

[28] Clouse RE, Richter JE, Heading RC, Janssens J, Wilson JA (1999) Functional esophageal disorders. Gut 45 (Suppl 2): II31-II36

[29] Tutuian R, Castell DO (2004) Rumination documented by using combined multichannel intraluminal impedance and manometry. Clin Gastroenterol Hepatol 2: 340-343

[30] Bredenoord AJ, Weusten BL, Sifrim D, Timmer R, Smout AJ (2004) Aerophagia, gastric, and supragastric belching: a study using intraluminal electrical impedance monitoring. Gut 53: 1561-1565 